\title{
Clinical utility of hepatitis B surface antigen levels during the natural history and treatment of chronic hepatitis $\mathrm{B}$ infection
}

\author{
Mustafa Çelik, Mahmut Arabul, Cem Çekiç, Sezgin Vatansever, Serkan İpek, Fatih Aslan, Belkıs Ünsal \\ Department of Gastroenterology, Atatürk Training and Research Hospital, Izmir, Turkey
}

Prz Gastroentereol 2014, 9, 3: 164-167

DOI: $10.5114 /$ pg.2014.43758

Key words: chronic hepatitis B, hepatitis B surface antigen levels.

\begin{abstract}
Address for correspondence: Cem Çekiç PhD, Department of Gastroenterology, Atatürk Training and Research Hospital, 35360 Izmir, Turkey, phone: +902322444444, e-mail: cekiccem@yahoo.com
\end{abstract}

\begin{abstract}
Introduction: Hepatitis B surface antigen (HBsAg) level quantitation may be helpful for understanding the natural history of the disease and its response to treatment.

Aim: To determine the serum HBsAg levels during the different phases of chronic hepatitis B (CHB) infection and $\mathrm{HBs} A g$ levels of patients who are on treatment with oral antiviral drugs.

Material and methods: Patients were categorized in four groups: 9 patients in the immune clearance (IC) phase, 46 patients in the inactive carrier (INC) phase, 25 patients in the reactivated HBeAg negative disease (END) phase and $60 \mathrm{HBeAg}$ negative patients who were on treatment with oral antiviral drugs. HBsAg levels were compared between all groups. HBsAg and HBV DNA levels were compared in three phases of HBV infection. Patients on treatment were divided into two groups, taking lamivudine $(\mathrm{L})$ and taking tenofovir $(\mathrm{T})$. HBsAg levels were compared between END, $\mathrm{L}$ and $\mathrm{T}$ groups.

Results: The HBsAg levels were different between each phase of $\mathrm{CHB}(p<0.0001)$. HBsAg levels were highest in the IC phase and lowest in the INC phase. The HBsAg/HBV DNA ratio was significantly higher in the INC phase than the END and IC phases $(p<0.0001)$. HBsAg levels were higher in the END phase than the INC phase $(p<0.0001)$ and higher than the treatment group $(p=0.007)$. The HBsAg levels had a good correlation with HBV DNA in the natural course of CHB $(r=0.72, p<0.0001)$. HBsAg levels were higher in the END group than the $L$ and T groups $(p<0.05)$. HBsAg levels were higher in the $L$ than the $T$ group $(p<0.05)$.

Conclusions: This study demonstrates that HBsAg levels vary during the natural history of chronic hepatitis B infection. Also, the monitoring of HBsAg levels may help us to determine the best management strategy and to decide future treatment algorithms.
\end{abstract}

\section{Introduction}

Hepatitis B surface antigen (HBsAg) was the first discovered hepatitis $B$ virus (HBV) protein and the detection of HBsAg is the cornerstone of hepatitis B infection diagnosis [1]. Recent data from clinical trials have shown that quantitation of HBsAg levels may be helpful for understanding the natural history of the disease and its response to treatment.

The natural history of chronic hepatitis $B(\mathrm{CHB})$ is divided into four different phases: the immune-tolerant phase, the immune-clearance phase (IC), inactive carrier (INC) and reactivated HBeAg negative disease (END) [2]. Several cross-sectional studies have compared HBsAg and HBV DNA levels during different phases of $\mathrm{CHB}$.
Both HBsAg and HBV DNA levels vary during the natural course of the infection. HBsAg and HBV DNA levels were highest during the immunotolerance phase and lowest in the inactive carrier phase $[3,4]$. The HBeAg-negative patients have higher HBsAg and HBV DNA levels than inactive carriers [5]. A cutoff level lower than $2000 \mathrm{lU} / \mathrm{ml}$ HBV DNA is used to define the inactive carrier phase of hepatitis B infection but this cutoff level is still doubtful. Inactive carriers and END may be classified better by using cutoff levels of HBsAg and HBV DNA together. Inactive carriers can be classified with $94 \%$ to $100 \%$ accuracy by using a 1 to $2 \times 10^{3} \mathrm{lU} / \mathrm{ml}$ cutoff level for HBsAg and a $2 \times 10^{3} \mathrm{IU} / \mathrm{ml}$ cutoff level for HBV DNA together $[6,7]$.

$\mathrm{HBsAg}$ seroconversion is the ultimate goal of $\mathrm{HBV}$ infection therapy [2]. One important indicator of viral 
persistence is covalently closed circular DNA (cccDNA). cccDNA is considered as a surrogate marker of infected cells, which serves as the template for viral replication inside hepatocytes [8]. Reduction in cccDNA level after antiviral therapy is associated with a sustained virologic response [9]. Good correlations have been found between the absolute levels as well as the changes of serum HBsAg and cccDNA before and after antiviral therapy [10].

HBsAg quantitation may be a promising prognostic marker during the natural history of HBV infection and antiviral therapy.

\section{Aim}

We aimed to determine the serum HBsAg levels during the different phases of the natural history of $\mathrm{CHB}$ and also HBsAg levels of patients who are on treatment with oral antiviral drugs. We also aimed to investigate the correlation between $\mathrm{HBsAg}$ and HBV DNA levels.

\section{Material and methods}

One hundred and forty patients with chronic hepatitis B infection were included in this prospective study. The patients were recruited in Izmir Atatürk training and research hospital. No individuals were included who had hepatitis delta virus, hepatitis C virus or human immunodeficiency virus coinfection, acute infection with EBV or CMV, alcohol consumption (> 20 g/day), immunosuppressive drug use or malignant comorbidities. Patients with autoimmune hepatitis were excluded from this study.

Patients were classified into a phase of $\mathrm{CHB}$ according to the recently published European Association for the Study of the Liver (EASL) clinical practice guidelines [2].

Patients were categorized in four groups. Three different phases of $\mathrm{CHB}$ infection were included in the study: 9 patients in the IC phase (positive HBsAg for at least 6 months, positive $\mathrm{HBeAg}$, persistent elevation of ALT, HBV DNA > $20000 \mathrm{IU} / \mathrm{ml}), 46$ patients in INC phase (positive HBsAg for at least 6 months, positive anti-HBeAg antibody, normal ALT levels more than two times in a year follow-up, HBV DNA $<2000 \mathrm{lU} / \mathrm{ml}$ ), 25 patients in END phase (positive $\mathrm{HBsAg}$ for at least 6 months, positive anti-HBeAg antibody, persistent elevation of ALT, HBV DNA > $20000 \mathrm{lU} / \mathrm{ml}$ ). Also, $60 \mathrm{HBeAg}$ negative patients who were on treatment with oral antiviral drugs and had negative HBV DNA over one year were included in the treatment group. $\mathrm{HBsAg}$ levels were compared between all groups. The correlations between HBsAg and HBV DNA levels were determined in the natural course of HBV infection. Also, patients on treatment were divided into two groups, taking lamivudine $(\mathrm{L})$ and taking tenofovir $(\mathrm{T})$. HBsAg levels were compared between the END group, $L$ group $(n=30)$ and T group $(n=21)$. Informed consent was obtained from all patients. The study was approved by the local Ethics Committees for Medical Research in accordance with the 1975 Declaration of Helsinki. Serum samples were stored at $-70^{\circ} \mathrm{C}$ until use.

\section{Quantitative serum HBsAg assay}

Serum HBsAg levels were quantified using the Roche Elecsys HBsAg II Quant assay (Roche Diagnostics, Mannheim, Germany). Quantitative HBsAg levels were reported in $\mathrm{IU} / \mathrm{ml}$ with a dynamic range of $0.05-52.000 \mathrm{IU} / \mathrm{ml}$.

\section{HBV DNA measurement}

Serum HBV DNA was measured using an Abbott real-time HBV assay (Abbott Diagnostics, Santa Clara, CA) with a detection limit of 10-1 $000000000 \mathrm{pg} / \mathrm{ml}$ $(1 \mathrm{pg} / \mathrm{ml}=3.4$ copies $/ \mathrm{ml}$ ).

\section{Statistical analysis}

The Kolmogorov-Smirnov test was used to assess the normality of the data. Comparisons between the two groups were made using the Mann-Whitney U-test or independent sample $T$-test according to the distribution of the data. Comparisons between more than two groups were made using the Kruskal-Wallis test or ANOVA according to the distribution of the data. Correlations between groups were evaluated with Pearson's correlation test. A level of $p$ less than 0.05 was considered statistically significant. All analyses were two-tailed and conducted using the computer-based statistics software program SPSS version 17.0 (SPSS Inc., Chicago, IL, USA).

\section{Results}

Patients in the IC phase were younger than patients in the INC $(p<0.01)$ or END phase $(p<0.01)$. HBsAg levels were different between each phase of CHB (between treatment-END groups; $p=0.007$, treatment-INC groups; $p<0.0001$, treatment-IC groups; $p<0.0001$, END-INC groups; $p<0.0001$, END-IC groups; $p=0.02$, INC-IC groups; $p<0.0001)$. HBsAg levels were highest in the IC phase and lowest in the INC phase. The HBsAg/ HBV DNA ratio was significantly higher in the INC phase than END $(p<0.0001)$ and IC phases $(p<0.0001)$ (Table I). HBsAg levels were higher in the END phase than the INC phase $(p<0.0001)$ and also higher than the treatment group ( $p=0.007)$. HBsAg levels had a good correlation with HBV DNA in the natural course of $\mathrm{CHB}$ $(r=0.72, p<0.0001)$ (Figure 1). HBsAg levels were compared between the END group, L group and T group. 
Table I. Comparison between groups with regard to age, sex, ALT, HBsAg and HBV DNA levels

\begin{tabular}{|c|c|c|c|c|c|}
\hline Variable & $\begin{array}{l}\text { Treatment group } \\
\quad(n=60)\end{array}$ & $\begin{array}{l}\text { END phase } \\
\quad(n=25)\end{array}$ & $\begin{array}{l}\text { INC phase } \\
(n=46)\end{array}$ & $\begin{array}{c}\text { IC phase } \\
(n=9)\end{array}$ & Value of $p$ \\
\hline HBeAg status & $(-)$ & $(-)$ & $(-)$ & $(+)$ & \\
\hline HBsAg levels & $5490 \pm 7180$ & $8360 \pm 6562$ & $2456 \pm 4055$ & $59097 \pm 55093$ & $<0.0001$ \\
\hline HBsAg log & $3.43 \pm 0.59$ & $3.79 \pm 0.41$ & $2.78 \pm 0.84$ & $4.50 \pm 0.59$ & $<0.0001$ \\
\hline HBV DNA & $13.9 \pm 44.9$ & $0.9 \times 10^{7} \pm 2.5 \times 10^{7}$ & $912 \pm 1212$ & $6.2 \times 10^{8} \pm 7.5 \times 10^{8}$ & $<0.0001$ \\
\hline HBV DNA log10 & $1.77 \pm 0.38$ & $5.70 \pm 1.27$ & $2.49 \pm 0.75$ & $8.28 \pm 0.85$ & $<0.0001$ \\
\hline HBsAg log/HBV DNA log10 & $1.88 \pm 0.61$ & $0.69 \pm 0.16$ & $1.18 \pm 0.42$ & $0.55 \pm 0.06$ & $<0.0001$ \\
\hline Age [year] & $47.8 \pm 13.0$ & $39.3 \pm 10.8$ & $45.3 \pm 11.4$ & $35.3 \pm 16.1$ & 0.004 \\
\hline Gender (female/male) & $24 / 36$ & $13 / 12$ & $24 / 22$ & $5 / 4$ & $>0.05$ \\
\hline ALT [IU/ml] & $26.5 \pm 10.9$ & $89 \pm 123$ & $27.6 \pm 11.2$ & $124 \pm 122$ & $<0.0001$ \\
\hline
\end{tabular}

END phase - HBeAg negative disease phase, INC phase - inactive carrier phase, IC phase-immune clearance phase

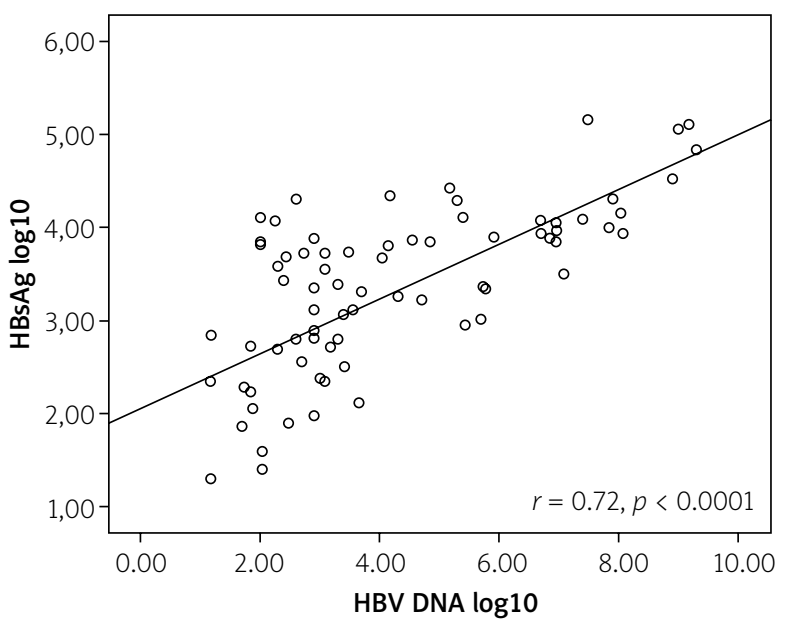

Figure 1. Relationship between HBsAg and HBV DNA levels during the $\mathrm{CHB}$ infection

HBsAg levels were higher in the END group than the L group ( $p<0.01$ ) and T group ( $p<0.01)$. HBsAg levels were higher in the $L$ group than the $T$ group $(p<0.01)$ (Table II).

\section{Discussion}

The natural history of $\mathrm{CHB}$ is usually determined by using HBeAg status, ALT and HBV DNA levels [11]. There are limited data about the hepatitis B surface antigen levels in the natural history of CHB. In our study we found that HBsAg and HBV DNA levels differ during the natural history of chronic hepatitis $B$ infection in parallel to each other. The INC phase was characterized by the highest $\mathrm{HBsAg} / \mathrm{HBV}$ DNA ratio. Also the correlation of $\mathrm{HBsAg}$ and HBV DNA during the natural course of $\mathrm{CHB}$ was an interesting observation. These results suggest that $\mathrm{HBsAg}$ quantitation, combined with HBV DNA, may be useful for better determination of the phases of CHB infection.

Quantitative serum HBsAg was a good surrogate marker for both cccDNA and total intrahepatic HBV DNA [10]. Recent studies have suggested that the quantitation of HBsAg in HBeAg negative HBV infection or HBV/ hepatitis delta virus dual infection has potential for monitoring the response to interferon and oral antiviral maintenance therapy $[12,13]$.

In interferon-based therapeutic regimens, the early drop in serum HBsAg levels has a high predictive value for a sustained virological response in both HBeAg-positive and HBeAg-negative patients [14, 15]. However, limited data are available on the potential usefulness

Table II. Comparison of HBsAg levels among the END, lamivudine and tenofovir groups

\begin{tabular}{lcccc} 
Variable & Lamivudine group $(n=30)$ & Tenofovir group $(n=21)$ & END group $(n=25)$ & Value of $p$ \\
\hline HBsAg levels & $6224 \pm 7996$ & $3895 \pm 6300$ & $8630 \pm 6562$ & $3.79 \pm 0.41$ \\
\hline HBsAg log & $3.46 \pm 0.66$ & $3.27 \pm 0.56$ & $39.3 \pm 10.8$ & $<01$ \\
\hline Age & $46.6 \pm 13.7$ & $50.0 \pm 11.1$ & $13 / 12$ & $<0.01$ \\
\hline Gender (F/M) & $15 / 15$ & $6 / 15$ & $89.0 \pm 123$ & $<.05$ \\
\hline ALT $[\mathrm{IU} / \mathrm{ml}]$ & $26.0 \pm 12.0$ & $26.1 \pm 8.4$ & 0.0001
\end{tabular}


of HBsAg titer monitoring during long-term NA treatment. Oral antiviral drugs may decrease the HBsAg levels $[13,16,17]$. We found that HBsAg levels are lower in $\mathrm{HBeAg}$ negative patients who are treated with an oral antiviral drug than treatment-naive $\mathrm{HBeAg}$ negative patients. Also, HBsAg titers are lower in tenofovir-treated patients than lamivudine-treated patients.

\section{Conclusions}

This study demonstrates that HBsAg levels differ during the natural history of chronic hepatitis $B$ infection and HBsAg levels are associated with HBV DNA levels. These findings may help us to understand the natural course of hepatitis B infection, as an example for identification of true inactive carriers. Also, the monitoring of HBsAg levels may help us to determine the best management strategy and HBsAg quantification may help us to decide future treatment algorithms for both immune-modulator therapy and oral nucleos(t)ide analogue therapy.

\section{References}

1. Blumberg BS, Alter HJ, Visnich S. A "New" antigen in leukemia sera. JAMA 1965; 191: 541-6.

2. European Association for the Study of the Liver. EASL Clinical Practice Guidelines: management of chronic hepatitis B. J Hepatol 2009; 50: 227-42.

3. Chan HL, Wong VW, Wong GL, et al. A longitudinal study on the natural history of serum hepatitis B surface antigen changes in chronic hepatitis B. Hepatology 2010; 52: 1232-41.

4. Jaroszewicz J, Calle Serrano B, Wursthorn K, et al. Hepatitis B surface antigen ( $\mathrm{HBsAg}$ ) levels in the natural history of hepatitis B virus (HBV)-infection: a European perspective. J Hepatol 2010; 52: 514-22.

5. Nguyen T, Thompson AJ, Bowden S, et al. Hepatitis B surface antigen levels during the natural history of chronic hepatitis $B$ : a perspective on Asia. J Hepatol 2010; 52: 508-513.

6. Brunetto MR, Oliveri F, Colombatto P, et al. Hepatitis B surface antigen serum levels help to distinguish active from inactive hepatitis B virus genotype D carriers. Gastroenterology 2010; 139: 483-90.

7. Martinot-Peignoux M, Lada O, Cardoso AC, et al. Quantitative HBsAg: a new specific marker for the diagnosis of HBsAg inactive carriage. Hepatology 2010; 52: 992.

8. Brunetto MR. A new role for an old marker, HBsAg. J Hepatol 2010; 52: 475-7.

9. Sung JJ, Wong ML, Bowden S, et al. Intrahepatic hepatitis B virus covalently closed circular DNA can be a predictor of sustained response to therapy. Gastroentereology 2005; 128: 1890-7.

10. Chan HL, Wong VW, Tse AM, et al. Serum hepatitis B surface antigen quantitation can reflect hepatitis $B$ virus in the liver and predict treatment response. Clin Gastroenterol Hepatol 2007; 5: 1462-8.
11. Chan HL, Wong GL, Wong VW. A review of the natural history of chronic hepatitis B in the era of transient elastography. Antivir Ther 2009; 14: 489-99.

12. Manesis EK, Schina M, Le Gal F, et al. Quantitatvive analysis of hepatitis D virus RNA and hepatitis B surface antigen serum levels in chronic delta hepatitis improves treatment monitoring. Antivir Ther 2007; 12: 381-8.

13. Manesis EK, Hadziyannis ES, Angelopoulou OP, et al. Prediction of treatment-related HBsAg loss in $\mathrm{HBeAg}$ negative chronic hepatitis B: a clue from serum HBsAg levels. Antivir Ther 2007; 12: 73-82.

14. Moucari R, Mackiewicz V, Lada O, et al. Early serum HBsAg: a strong predictor of sustained virological response to pegylated interferon alfa-2a in HBeAg-negative patients. Hepatology 2009; 49: 1151-7.

15. Moucari R, Korevaar A, Lada O, et al. High rates of HBsAg seroconversion in $\mathrm{HBeAg}$-positive chronic hepatitis $\mathrm{B}$ patients responding to interferon: a long-term follow up study. J Hepatol 2009; 50: 1084-92.

16. Borgniet O, Parvaz P, Bouix C, et al. Clerance of serum HBsAg and antiHBs seroconversion following antiviral therapy for chronic hepatitis B. J Med Virol 2009; 81: 1336-42.

17. Gramenzi A, Loggi E, Micco L, et al. Serum hepatitis B surface antigen monitoring in long-term lamivudine-treated hepatitis B virus patients. J Viral Hepatitis 2011; 18: 468-74.

Received: $\quad 18.06 .2013$

Accepted: $\quad 30.05 .2014$ 